\title{
Frequent MED12 mutations in phyllodes tumours of the breast
}

\author{
M Yoshida ${ }^{1}$, S Sekine ${ }^{\star}, 1,2$, R Ogawa $^{2}$, H Yoshida ${ }^{1}$, A Maeshima ${ }^{1}$, Y Kanai ${ }^{2}$, T Kinoshita ${ }^{3}$ and A Ochiai ${ }^{1}$ \\ ${ }^{1}$ Pathology and Clinical Laboratories, National Cancer Center Hospital, Tokyo 104-0045, Japan; ${ }^{2}$ Division of Molecular Pathology, \\ National Cancer Center Research Institute, Tokyo 104-0045, Japan and ${ }^{3}$ Breast Surgery Division, National Cancer Center Hospital, \\ Tokyo 104-0045, Japan
}

Background: Phyllodes tumours are rare fibroepithelial tumours of the breast, that include benign, borderline, and malignant lesions. Although the molecular basis of phyllodes tumours largely remains unknown, a recent exome study identified MED12 mutations as a sole recurrent genetic alteration in fibroadenoma, a common benign fibroepithelial tumour that shares some histological features with the phyllodes tumour.

Methods: Forty-six phyllodes tumours and 58 fibroadenomas of the breast were analysed for MED12 mutations by using Sanger sequencing.

Results: MED12 mutations were identified in 37 out of the 46 phyllodes tumours (80\%). The prevalence of MED12 mutations was similar among benign $(15 / 18,83 \%)$, borderline $(12 / 15,80 \%)$, and malignant tumours (10/13, 77\%). MED12 mutations were also identified in 36 of the 58 fibroadenomas (62\%). The mutations were frequent among intracanalicular-type (24/32, 75\%) and complex-type lesions (4/6, 67\%), but were significantly less common among the pericanalicular-type lesions (8/20, 40\%). A microdissection-based analysis showed that MED12 mutations were confined to the stromal components in both phyllodes tumours and fibroadenomas.

Conclusions: MED12 mutations were frequent among the phyllodes tumours of the breast, regardless of the tumour grade. Phyllodes tumours and fibroadenomas share, at least in part, a common genetic background.

Fibroepithelial tumours of the breast are a heterogeneous group of tumours consisting of variable proportions of epithelial and stromal components (Tavassoli and Eusebi, 2009; Tan et al, 2012; Yang et al, 2014). Fibroadenoma and phyllodes tumour are the major histological entities of this group of tumours. Fibroadenomas are common benign neoplasms that predominantly affect young adults. Studies on autopsy cases have reported a prevalence of fibroadenoma of 15-23\% (Frantz et al, 1951; Bhathal et al, 1985; Bartow et al, 1987; Nielsen et al, 1987). Phyllodes tumours are rare, accounting for less than $1 \%$ of all breast tumours and include benign, borderline, and malignant lesions (Reinfuss et al, 1996; Tavassoli and Eusebi, 2009), some phyllodes tumours can lead to local recurrences and distant metastasis (Chaney et al, 2000).
Phyllodes tumours are histologically characterised by a pronounced intracanalicular growth and increased cellularity (Tavassoli and Eusebi, 2009; Tan et al, 2012; Yang et al, 2014). Additionally, they may exhibit nuclear atypia and increased mitotic counts, and they may have an obvious sarcomatous component. However, the histological discrimination of phyllodes tumours from fibroadenomas sometimes can be a diagnostic challenge. In particular, a significant overlap exists in the histological features of intracanalicular-type fibroadenomas and benign phyllodes tumours, and no clear-cut morphological criteria exist for distinguishing these two lesions (Giri, 2009; Lawton et al, 2014). Furthermore, some studies have suggested the potential progression of fibroadenomas to phyllodes tumours (Noguchi et al, 1995; Hodges et al, 2009; Abe et al, 2011). 
The molecular basis for the tumourigenesis of fibroepithelial breast tumours has been poorly understood, but a recent study by using massively parallel sequencing identified MED12 mutation as the sole and highly recurrent genetic alteration of fibroadenomas (Lim et al, 2014). Based on its somatic nature and high prevalence, the MED12 mutation is expected to be a critical driver mutation in the development of fibroadenoma. Interestingly, uterine leiomyomas have also shown to frequently harbour MED12 mutations of a similar spectrum, implying a common role of MED12 mutations in the development of these two oestrogen-dependent neoplasms (Makinen et al, 2011; McGuire et al, 2012; Matsubara et al, 2013; Kampjarvi et al, 2014). A recent study showed that uterine leiomyoma-associated MED12 mutations disrupted the MED12CyclinC interface and resulted in loss of mediator-associated CDK activity, suggesting a role in aberrant CDK8/19 activity (Turunen et al, 2014).

We postulated that phyllodes tumours might share a common genetic background with fibroadenomas based on the partial morphological resemblance of these tumours and the results of previous reports suggesting a histogenetic relationship between fibroadenomas and phyllodes tumours. In the present study, we conducted a mutation analysis of MED12 in a series of fibroadenomas and phyllodes tumours.

\section{MATERIALS AND METHODS}

This study was approved by the Ethics Committee of the National Cancer Center, Tokyo, Japan. All the tissue samples were obtained at the National Cancer Center Hospital, Tokyo, Japan. The resected specimens were routinely fixed in $10 \%$ formalin and embedded in paraffin. This study examined 104 fibroepithelial tumours of the breast, including 46 phyllodes tumours and 58 fibroadenomas. The phyllodes tumours were subclassified according to the WHO classification as benign, borderline, or malignant lesions, based on semi-quantitative assessments of stromal cellularity, cellular pleomorphism, mitotic activity, tumour margin/border appearance, and stromal distribution/overgrowth (Figure 1A-C) (Tan et al, 2012). Fibroadenomas were primarily classified into intracanalicular- and pericanalicular-types depending on the predominant growth patterns (Figure 1D and E). In addition, fibroadenomas showing cyst formation, sclerosing adenosis, and/or apocrine metaplasia were classified as complex type (Figure 1F) (Dupont et al, 1994).

Sections of tumour specimens were deparaffinised, stained briefly with hematoxylin and subjected to DNA extraction. The stromal components of phyllodes tumours and fibroadenomas were dissected by using sterilised toothpicks under a microscope. Non-tumourous areas were separately dissected when a sufficient amount of tissue was available. The dissected samples were incubated in $50 \mu \mathrm{l}$ DNA extraction buffer $(50 \mathrm{~mm}$ Tris- $\mathrm{HCl}, \mathrm{pH}$ 8.0, $1 \mathrm{~mm}$ ethylenediaminetetra-acetic acid, $0.5 \% \mathrm{v} / \mathrm{v}$ Tween 20 , $200 \mu \mathrm{g} \mathrm{ml}^{-1}$ proteinase $\mathrm{K}$ ) at $50{ }^{\circ} \mathrm{C}$ overnight. Proteinase $\mathrm{K}$ was inactivated by heating at $100{ }^{\circ} \mathrm{C}$ for $10 \mathrm{~min}$. Then, the samples were subjected to polymerase chain reaction (PCR) by using a pair of primers encompassing the frequently mutated region of MED12 (5'-ACTCTCCCACCCCTTCCCCC- $3^{\prime}$ and $5^{\prime}$-GGCAGGATTGAA GCTGACGTTC-3'; Matsubara et al, 2013). The PCR products were purified by using the Agencourt AMPure XP kit (Beckman Coulter, Brea, CA, USA). The isolated PCR products were then bidirectionally sequenced by using a 3130 Genetic Analyzer (Applied Biosystems, Foster City, CA, USA). Mutations were confirmed by using at least two independent analyses.

A microdissection-based analysis was performed in selected cases with a MED12 mutation. The epithelial and stromal components were microdissected separately by using a laser microdissection system (MMI CellCut system; Molecular Machines and Industries,

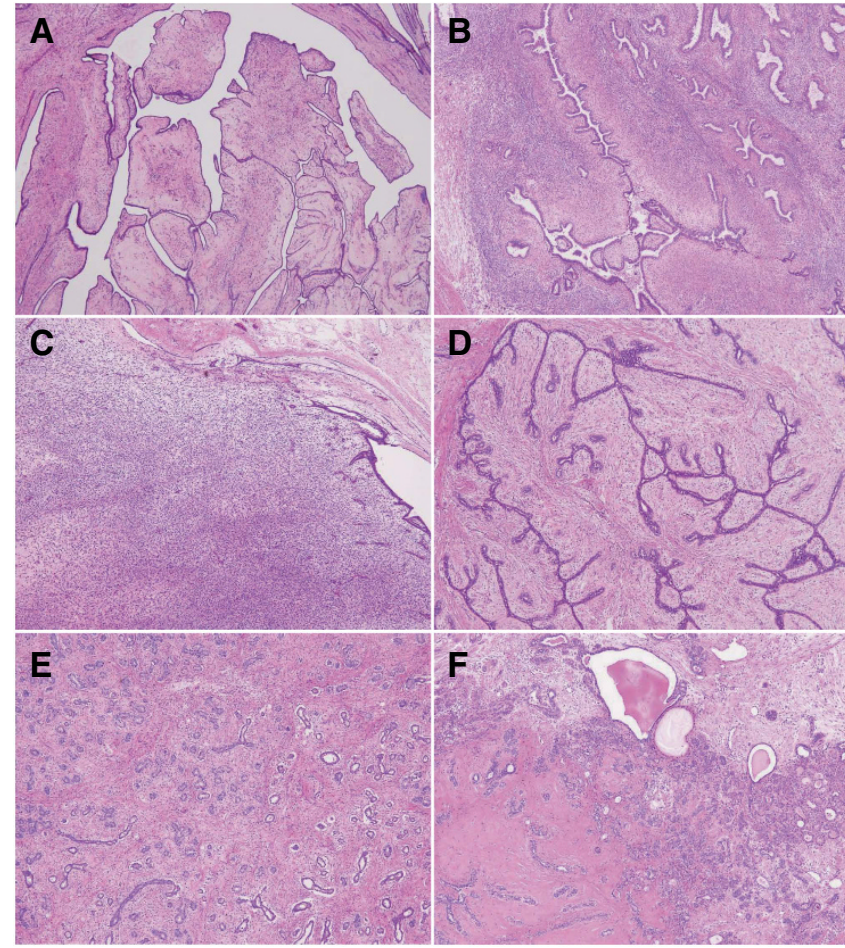

Figure 1. Representative histology of phyllodes tumour $(\mathbf{A}-\mathbf{C})$ and fibroadenoma (D-F). (A) Benign phyllodes tumour showing a classical leaf-like structure. (B) Borderline phyllodes tumour with stromal expansion resulting in duct compression. (C) Malignant phyllodes tumour showing prominent stromal overgrowth and a high cellularity. (D) Intracanalicular-type fibroadenoma. The ducts are compressed and exhibit a slit-like structure. (E) Pericanalicular-type fibroadenoma. The pericanalicular proliferation of the stroma and tubular glands are seen. (F) Complex fibroadenoma. Cyst formation and an area of stromal hyalinisation are noted.

Glattbrugg, Switzerland). The isolated samples were then examined for the presence of MED12 mutations as described above.

The Fisher exact test was used to analyse categorical data. The Mann-Whitney U test or the Kruskal-Wallis test were used for the analysis of continuous variables. $P<0.05$ was considered statistically significant.

\section{RESULTS}

The phyllodes tumours were histologically subclassified into 18 benign, 15 borderline, and 13 malignant lesions (Table 1). Patients with malignant or borderline tumours were significantly older than those with benign lesions $(P=0.045)$. Malignant tumours were larger than benign and borderline tumours $(P=0.034)$. The fibroadenomas consisted of 32 intracanalicular-type, 20 pericanalicular-type, and 6 complex-type lesions. The pericanalicular-type fibroadenomas were significantly larger than the intracanaliculartype lesions $(P=0.020)$.

MED12 mutations were identified in 37 (80\%) phyllodes tumours and 36 (62\%) fibroadenomas (Table 1). Even though MED12 mutations tended to be more prevalent in the phyllodes tumours, the difference did not reach the statistical significance $(P=0.053)$. The prevalence of MED12 mutations was similar among the phyllodes tumours of different tumour grades. Among the fibroadenomas, MED12 mutations were more common among the intracanalicular-type lesions than among the pericanaliculartype lesions $(P=0.019)$. Non-tumour tissue samples were available for 26 phyllodes tumours and in 50 fibroadenomas, but none of 
Table 1. MED12 mutations in phyllodes tumours and fibroadenomas of the breast

\begin{tabular}{|c|c|c|c|c|c|c|c|}
\hline Histology & Number of cases & Age, year old & $P$-value & Tumour size, mm & $P$-value & MED12 mutation & $P$-value \\
\hline Phyllodes tumour & 46 & $48.5(26-67)$ & & $46.5(10-160)$ & & $37(80 \%)$ & \\
\hline Benign & 18 & $41.5(26-65)$ & $0.045^{a}$ & $33.5(10-100)$ & $0.034^{a}$ & 15 (83\%) & $0.90^{\mathrm{a}}$ \\
\hline Borderline & 15 & $55(26-67)$ & & $48(28-130)$ & & $12(80 \%)$ & \\
\hline Malignant & 13 & $55(36-64)$ & & $75(17-160)$ & & $10(77 \%)$ & \\
\hline Fibroadenoma & 58 & $39(18-66)$ & $9.0 \times 10^{-6} \mathrm{~b}$ & $15(6-45)$ & $6.5 \times 10^{-11 b}$ & $36(62 \%)$ & $0.053^{b}$ \\
\hline Intracanalicular & 32 & $39(21-63)$ & $0.78^{c}$ & $14(6-45)$ & $0.020^{c}$ & $24(75 \%)$ & $0.019^{c}$ \\
\hline Pericanalicular & 20 & $37.5(18-66)$ & & $24(6-45)$ & & $8(40 \%)$ & \\
\hline Complex & 6 & $38.5(32-46)$ & & $10(9-16)$ & & $4(67 \%)$ & \\
\hline \multicolumn{8}{|c|}{$\begin{array}{l}\text { Age and tumour size are indicated as the median (range). } \\
\text { a Benign vs borderline vs malignant grade. } \\
\text { b Phyllodes tumour vs fibroadenoma. } \\
\text { Intracanalicular vs pericanalicular subtype. }\end{array}$} \\
\hline
\end{tabular}

these samples showed mutations, indicating the somatic nature of these mutations.

Most of the mutations identified were missense mutations, inframe deletion/insertions within exon 2, or deletions involving a splice accepter site (Table 2, Figure 2A). Two cases had an intronic nucleotide change 8 base pairs upstream of exon 2, which was predicted to result in the insertion of two amino acids. In both phyllodes tumours and fibroadenomas, missense mutations affecting codon 44 were the most frequent (Figure 3). No apparent differences in the mutation patterns were observed among these tumours.

To test whether MED12 mutations were also present in the epithelial component, we performed a microdissection-based analysis of five MED12-mutated phyllodes tumours and five MED12-mutated fibroadenomas. The epithelial and stromal components were separately microdissected and analysed for the presence of mutations. As a result, MED12 mutations were identified exclusively in the stromal components in all the lesions that were examined (Figure 2B). Thus, the MED12 mutation was absent in the epithelial components of fibroadenomas and phyllodes tumours.

Finally, we tested whether the presence of MED12 mutations was related to the abnormal expressions of p53, p16, or $\mathrm{Rb}$. Immunohistochemistry showed p53 overexpression, p16 loss, and/ or $\mathrm{Rb}$ loss in nine $(69 \%)$ of the malignant phyllodes tumours and two $(13 \%)$ of the borderline phyllodes tumours, but in none of the benign phyllodes tumours or fibroadenomas (Supplementary Table 1, Supplementary Figure 1). We tested the correlation between the MED12 mutation status and the abnormal expression of each tumour suppressor gene product, but did not find any significant correlations (Supplementary Table 2).

\section{DISCUSSION}

The present study identified MED12 mutations in the majority of phyllodes tumours of the breast. The mutation frequency was similar among benign, borderline, and malignant lesions. These observations suggest that MED12 mutations have a critical role in the tumourigenesis of most phyllodes tumours and are not involved in the progression from benign to malignant tumours. While this study was under review, Cani et al (2015) also reported the presence of MED12 mutations in phyllodes tumours. Their study identified MED12 mutations in four out of five benign, four out of five borderline, and two out of five malignant phyllodes tumours. Even though the number of analysed tumours was rather limited, these findings are consistent with ours in that MED12 mutations were found to be present in phyllodes tumours regardless of the tumour grades. MED12 mutations were also common in fibroadenomas, similar to the results of a previous study reporting a mutation rate of $62 \%$ (Lim et al, 2014). The mutation frequency was significantly higher in intracanalicular-type lesions than in pericanalicular-type lesions. Since both phyllodes tumours and intracanalicular-type fibroadenomas are histologically characterised by an intracanalicular growth pattern (Tan et al, 2012), mutated MED12 may be involved in stromal cell proliferation and the formation of the characteristic morphology of these tumours.

Besides fibroadenomas, recurrent MED12 mutations have also been described in leiomyomas of the uterus, with reported frequencies of 52-82\% (Makinen et al, 2011; McGuire et al, 2012; Matsubara et al, 2013; Kampjarvi et al, 2014). The mutation spectrum in uterine leiomyomas is similar to that observed in fibroepithelial tumours of the breast identified in the present study. The comparable mutation patterns among these tumours imply a common biological role of MED12 mutation in the tumourigenesis of these tumours.

We also analysed the expressions of p53, p16, and Rb, which are often altered in malignant phyllodes tumours (Tse et al, 2002; Tan et al, 2005; Lae et al, 2007; Jones et al, 2008; Cimino-Mathews et al, 2013). In agreement with previous studies, more than half of the malignant phyllodes tumours showed p53 overexpression, and the loss of p16 and/or the loss of Rb, indicating the inactivation of these tumour suppressors (Jones et al, 2008; Yachida et al, 2012; Tan et al, 2014). These abnormalities were rare or absent in other groups of tumours. On the other hand, no significant correlations were observed between the abnormal expressions of these proteins and the MED12 mutation status. The inactivation of these tumour suppressors is likely to have a role in the progression of phyllodes tumours regardless of the presence or absence of MED12 mutations.

By definition, phyllodes tumours and fibroadenomas are biphasic tumours consisting of epithelial and stromal components (Tavassoli and Eusebi, 2009; Tan et al, 2012; Yang et al, 2014). However, the exclusive presence of MED12 mutations in the stromal components of fibroadenomas and phyllodes tumours, in agreement with a previous study, suggests that these tumours are primarily a stromal neoplasms (Lim et al, 2014). Consistent with this hypothesis, a study using an $\mathrm{X}$ chromosome inactivation-based clonality analysis showed that the stromal component was monoclonal, whereas the epithelial component was polyclonal, in the majority of phyllodes tumours that were examined (Kuijper et al, 2002). Another study examining the EGFR copy number by using fluorescent in situ hybridisation detected amplification events only in the stromal components of phyllodes tumours (Kersting et al, 2006). This study also demonstrated the presence of a tumour driver gene alteration that was restricted to the stromal component, similar to the results of present study.

On the other hand, the consistent presence of epithelial components in phyllodes tumours and fibroadenomas implies their requirement in the growth of these tumours. Importantly, several previous studies have suggested critical roles of epithelium-derived factors in the growth of stromal cells in these tumours (Sawhney et al, 1992; Sawyer et al, 2002). The interdependence between the non-neoplastic epithelial component and the neoplastic stromal 


\begin{tabular}{|c|c|c|c|}
\hline Nucleotide & $\begin{array}{l}\text { Amino } \\
\text { acid }\end{array}$ & $\begin{array}{l}\text { Mutated } \\
\text { cases in } \\
\text { phyllodes } \\
\text { tumour } \\
(n=46)\end{array}$ & $\begin{array}{l}\text { Mutated } \\
\text { cases in } \\
\text { fibro- } \\
\text { adenoma } \\
(n=58)\end{array}$ \\
\hline c. $122 \mathrm{~T}>\mathrm{A}$ & p.V41E & 0 & 2 \\
\hline c. $128 \mathrm{~A}>\mathrm{C}$ & p.Q43P & 1 & 0 \\
\hline c. $130 \mathrm{G}>\mathrm{A}$ & p.G44S & 1 & 2 \\
\hline c. $130 \mathrm{G}>\mathrm{C}$ & p.G44R & 3 & 0 \\
\hline c. $130 \mathrm{G}>\mathrm{T}$ & p.G44C & 1 & 2 \\
\hline c. $131 \mathrm{G}>\mathrm{A}$ & p.G44D & 8 & 13 \\
\hline c. $131 \mathrm{G}>\mathrm{C}$ & p.G44A & 2 & 1 \\
\hline c. $131 \mathrm{G}>\mathrm{T}$ & p.G44V & 2 & 3 \\
\hline c. $100-8 \mathrm{~T}>\mathrm{A}$ & p.E33_D34insPQ & 2 & 0 \\
\hline c. 100-2_141del44 & Loss of splice acceptor & 1 & 0 \\
\hline c.100-37_141del79insTTC & Loss of splice acceptor & 1 & 0 \\
\hline c.100-6_157del64 & Loss of splice acceptor & 1 & 0 \\
\hline c.100-7_134del42 & Loss of splice acceptor & 1 & 0 \\
\hline c.100-11_129del41 & Loss of splice acceptor & 0 & 1 \\
\hline c.100-22_100-1del22 & Loss of splice acceptor & 0 & 1 \\
\hline c.101A>G, c.104_112del9 & p.D34G, p.E35_T37 & 1 & 0 \\
\hline c.104_121dup18 & p.E35_N40dup & 1 & 0 \\
\hline c.104_121del18 & p.E35_N40del & 0 & 1 \\
\hline c.110_118dup9 & p.T37_L39dup & 0 & 1 \\
\hline c.111_155del45 & p.A38_S52del & 1 & 1 \\
\hline c.113_121del9 & p.A38_N40del & 0 & 1 \\
\hline c.117_134del18 & p.L39_G44del & 1 & 0 \\
\hline c.119_148del30 & p.N40T, p.V41_A50del & 0 & 1 \\
\hline c.120_125del6 & p.N40_V41del & 0 & 1 \\
\hline c.122_148del27 & p.V41_P49del & 1 & 1 \\
\hline c.122_157del36 & p.V41_S52del & 0 & 2 \\
\hline c.123_158del36 & p.K42_G53del & 1 & 0 \\
\hline c.123_164del42 & p.K42_E55del & 0 & 1 \\
\hline c.124_129dup6 & p.K42_Q43dup & 1 & 0 \\
\hline $\begin{array}{l}\text { c.124_150del27, } \\
\text { c.150T>C }\end{array}$ & $\begin{array}{l}\text { p.K42_A50del, } \\
\text { p.A50A }\end{array}$ & 1 & 0 \\
\hline c.133_147del15 & p.F45_P49del & 0 & 1 \\
\hline $\begin{array}{l}\text { c.129A>G, } \\
\text { c.133_150del18 }\end{array}$ & $\begin{array}{l}\text { p.Q43Q, } \\
\text { p.F45_A50del }\end{array}$ & 1 & 0 \\
\hline c.138_164del27 & p.N46_E55del & 1 & 0 \\
\hline c.141_167del27 & p.Q48_H56del & 2 & 0 \\
\hline c.146_166del21 & p.P49_E55del & 1 & 0 \\
\hline
\end{tabular}

component could conceivably produce the peculiar morphology of these fibroepithelial tumours. Interestingly, previous studies showed that allelic imbalance and monoclonality can also occur in the epithelium of phyllodes tumours (Sawyer et al, 2000; Kuijper et al, 2002). Considering the exclusive presence of MED12 mutations in the stromal component, clonal expansion may take place in the epithelial component independent of the stromal component.

The discrimination of phyllodes tumours and fibroadenomas is a clinically important issue because their management differs considerably. Fibroadenomas do not recur after complete resection, and conservative management, including a follow-up without excision, could be a valid option (Cant et al, 1995). On the other hand, phyllodes tumours, including benign lesions, may cause local recurrences and borderline and malignant lesions can develop
A
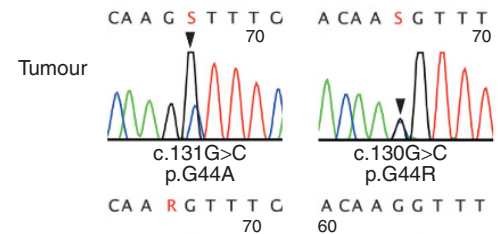

$T$
$T$
70

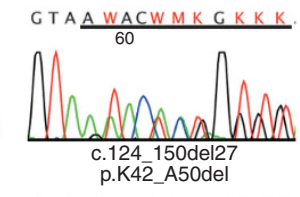

60
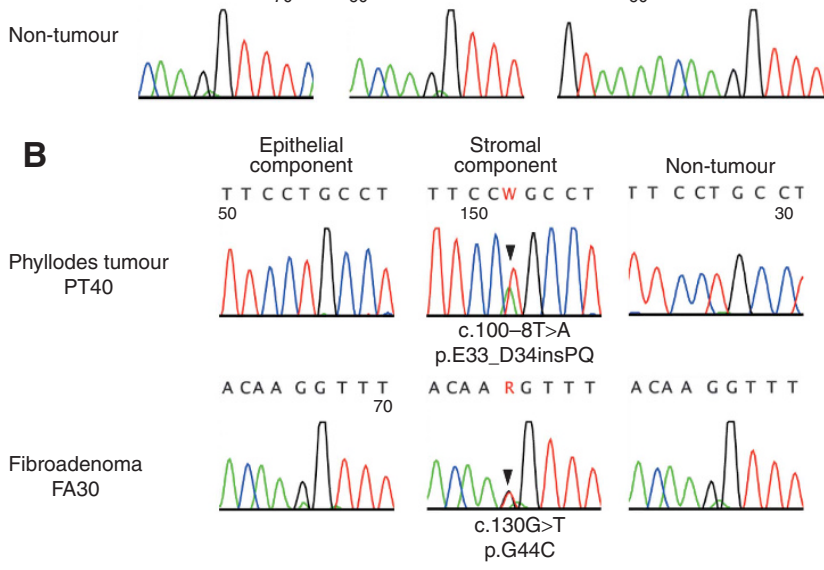

Figure 2. MED12 mutations in phyllodes tumours and fibroadenomas of the breast. (A) MED12 mutations in phyllodes tumours. (B) Microdissection-based analysis of MED12 mutations. Epithelial and stromal components of phyllodes tumours or fibroadenomas were separately microdissected and analysed for the presence of MED12 mutations. The arrowheads indicate missense mutations. The underline indicates deletions.

distant metastases (Chaney et al, 2000; Chen et al, 2005). However, the histological distinction of fibroadenomas and phyllodes tumours is based on several subjective findings, including the status of the tumour border, cellularity, and stromal atypia, and is not always straightforward (Lee et al, 2007; Tavassoli and Eusebi, 2009; Tan et al, 2012; Yang et al, 2014). A recent interobserver variability study highlighted a significant overlap in the morphology of cellular fibroadenomas and benign phyllodes tumours; a concordant diagnosis among 10 pathologists, who specialised in breast pathology, was made for only 2 out of 21 tumours (Lawton et al, 2014). The present study revealed that phyllodes tumours and fibroadenomas share a common genetic abnormality, in addition to their morphological features. This raises the possibility that fibroadenoma and phyllodes tumours represent a histomorphological continuum, rather than two distinct biological entities.

Some authors have suggested that phyllodes tumours arise from a terminal duct lobular unit de novo (Tan et al, 2012); on the other hand, several lines of evidence have suggested that phyllodes tumours might arise from fibroadenomas. A retrospective review of 36 malignant phyllodes tumours identified 11 cases that had transformed from fibroadenomas during a follow-up period (Abe et al, 2011). Also, some studies have reported that a subset of phyllodes tumours is associated with a previous history of resection for fibroadenomas (Lindquist et al, 1982; Chen et al, 2005). Furthermore, Noguchi et al (1995) analysed phyllodes tumours that developed following the resection of a fibroadenoma by using an $\mathrm{X}$ chromosome inactivation-based clonality analysis and suggested that phyllodes tumours could arise from preceding fibroadenomas. Although further evidence is required to reach a definite conclusion, the common presence of MED12 mutations in phyllodes tumours and fibroadenomas is consistent with the idea that fibroadenomas are potential precursors to phyllodes tumours.

The present study revealed the presence of MED12 mutations in the majority of phyllodes tumours, regardless of the tumour grade. Similar to 


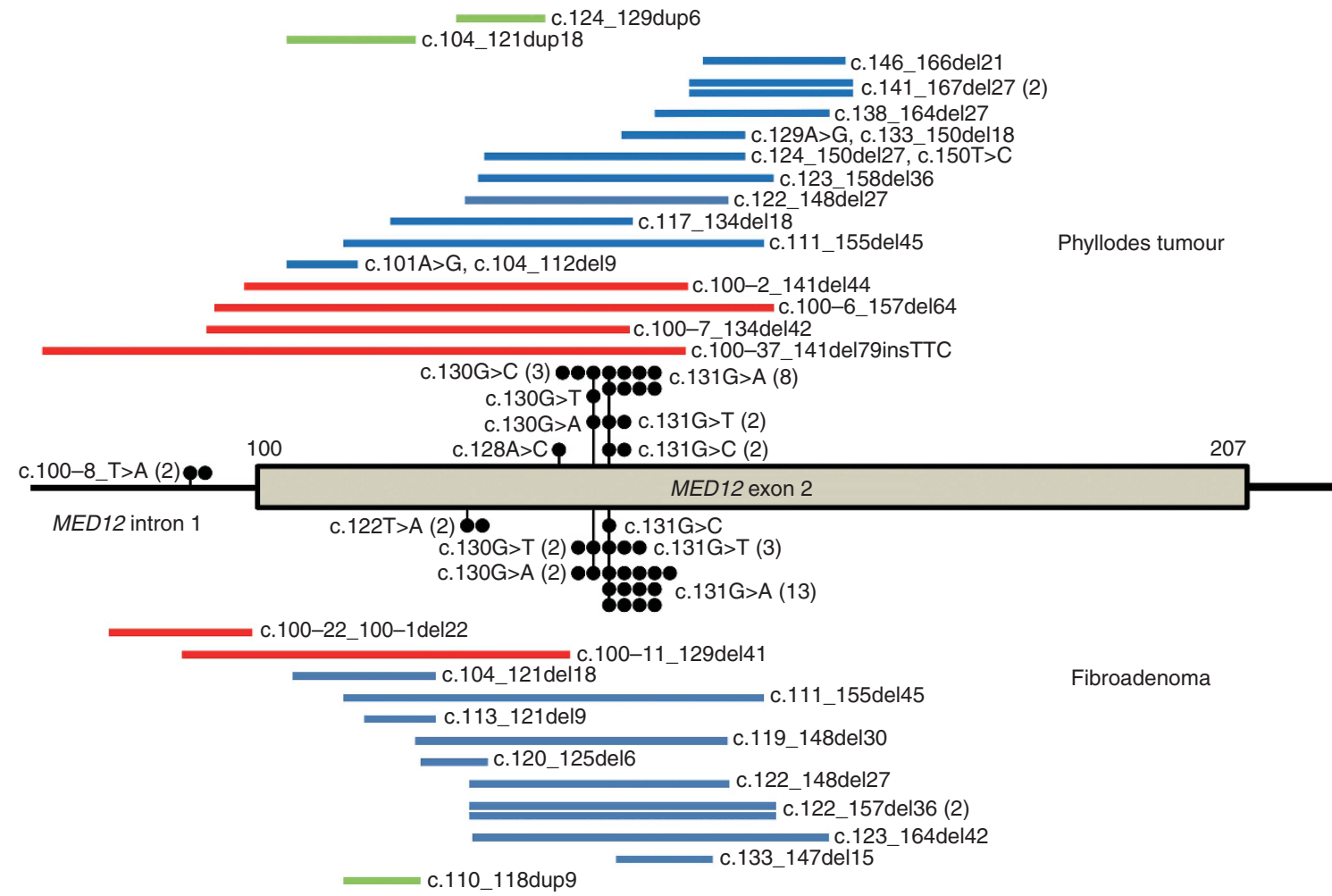

Figure 3. Distribution of MED12 mutations in phyllodes tumours and fibroadenomas of the breast. Closed circles, point mutations; red bars, deletions involving splice site acceptor; blue bars, in-frame deletions; green bars, duplications.

their involvement in fibroadenomas, MED12 mutations are thought to have a critical role in the tumourigenesis of phyllodes tumours. Furthermore, the common presence of MED12 mutations in these tumours may imply a histogenetic relationship between these two lesions.

\section{ACKNOWLEDGEMENTS}

We are grateful to Ms. Sachiko Miura, Ms. Toshiko Sakaguchi and Ms. Chizu Kina for the technical assistance. This work was supported in part by the National Cancer Center Research and Development Fund (26-A-4).

\section{REFERENCES}

Abe M, Miyata S, Nishimura S, Iijima K, Makita M, Akiyama F, Iwase T (2011) Malignant transformation of breast fibroadenoma to malignant phyllodes tumor: long-term outcome of 36 malignant phyllodes tumors. Breast Cancer 18(4): 268-272.

Bartow SA, Pathak DR, Black WC, Key CR, Teaf SR (1987) Prevalence of benign, atypical, and malignant breast lesions in populations at different risk for breast cancer. A forensic autopsy study. Cancer 60(11): 2751-2760.

Bhathal PS, Brown RW, Lesueur GC, Russell IS (1985) Frequency of benign and malignant breast lesions in 207 consecutive autopsies in Australian women. Br J Cancer 51(2): 271-278.

Cani AK, Hovelson DH, McDaniel AS, Sadis S, Haller MJ, Yadati V, Amin AM, Bratley J, Bandla S, Williams PD, Rhodes K, Liu CJ, Quist MJ, Rhodes DR, Grasso CS, Kleer CG, Tomlins SA (2015) Next-Gen sequencing exposes frequent MED12 mutations and actionable therapeutic targets in phyllodes tumors. Mol Cancer Res; e-pub ahead of print 15 January 2015.

Cant PJ, Madden MV, Coleman MG, Dent DM (1995) Non-operative manag ement of breast masses diagnosed as fibroadenoma. Br J Surg 82(6): 792-794.

Chaney AW, Pollack A, McNeese MD, Zagars GK, Pisters PW, Pollock RE, Hunt KK (2000) Primary treatment of cystosarcoma phyllodes of the breast. Cancer 89(7): 1502-1511.
Chen WH, Cheng SP, Tzen CY, Yang TL, Jeng KS, Liu CL, Liu TP (2005) Surgical treatment of phyllodes tumors of the breast: retrospective review of 172 cases. J Surg Oncol 91(3): 185-194.

Cimino-Mathews A, Hicks JL, Sharma R, Vang R, Illei PB, De Marzo A, Emens LA, Argani P (2013) A subset of malignant phyllodes tumors harbors alterations in the Rb/p16 pathway. Hum Pathol 44(11): 2494-2500.

Dupont WD, Page DL, Parl FF, Vnencak-Jones CL, Plummer Jr. WD, Rados MS, Schuyler PA (1994) Long-term risk of breast cancer in women with fibroadenoma. N Engl J Med 331(1): 10-15.

Frantz VK, Pickren JW, Melcher GW, Auchincloss Jr. H (1951) Indicence of chronic cystic disease in so-called "normal breasts; a study based on 225 postmortem examinations. Cancer 4(4): 762-783.

Giri D (2009) Recurrent challenges in the evaluation of fibroepithelial lesions. Arch Pathol Lab Med 133(5): 713-721.

Hodges KB, Abdul-Karim FW, Wang M, Lopez-Beltran A, Montironi R, Easley S, Zhang S, Wang N, MacLennan GT, Cheng L (2009) Evidence for transformation of fibroadenoma of the breast to malignant phyllodes tumor. Appl Immunohistochem Mol Morphol 17(4): 345-350.

Jones AM, Mitter R, Springall R, Graham T, Winter E, Gillett C, Hanby AM, Tomlinson IP, Sawyer EJ. Phyllodes Tumour Consortium (2008) A comprehensive genetic profile of phyllodes tumours of the breast detects important mutations, intra-tumoral genetic heterogeneity and new genetic changes on recurrence. J Pathol 214(5): 533-544.

Kampjarvi K, Park MJ, Mehine M, Kim NH, Clark AD, Butzow R, Bohling T, Bohm J, Mecklin JP, Jarvinen H, Tomlinson IP, van der Spuy ZM, Sjoberg J, Boyer TG, Vahteristo P (2014) Mutations in Exon 1 highlight the role of MED12 in uterine leiomyomas. Hum Mutat 35(9): 1136-1141.

Kersting C, Kuijper A, Schmidt H, Packeisen J, Liedtke C, Tidow N, Gustmann C, Hinrichs B, Wulfing P, Tio J, Boecker W, van Diest P, Brandt B, Buerger H (2006) Amplifications of the epidermal growth factor receptor gene (egfr) are common in phyllodes tumors of the breast and are associated with tumor progression. Lab Invest 86(1): 54-61.

Kuijper A, Buerger H, Simon R, Schaefer KL, Croonen A, Boecker W, van der Wall E, van Diest PJ (2002) Analysis of the progression of fibroepithelial tumours of the breast by PCR-based clonality assay. J Pathol 197(5): 575-581.

Lae M, Vincent-Salomon A, Savignoni A, Huon I, Freneaux P, Sigal-Zafrani B, Aurias A, Sastre-Garau X, Couturier J (2007) Phyllodes tumors of the breast segregate in two groups according to genetic criteria. Mod Pathol 20(4): 435-444. 
Lawton TJ, Acs G, Argani P, Farshid G, Gilcrease M, Goldstein N, Koerner F, Rowe JJ, Sanders M, Shah SS, Reynolds C (2014) Interobserver variability by pathologists in the distinction between cellular fibroadenomas and phyllodes tumors. Int J Surg Pathol 22: 695-698.

Lee AH, Hodi Z, Ellis IO, Elston CW (2007) Histological features useful in the distinction of phyllodes tumour and fibroadenoma on needle core biopsy of the breast. Histopathology 51(3): 336-344.

Lim WK, Ong CK, Tan J, Thike AA, Ng CC, Rajasegaran V, Myint SS, Nagarajan S, Nasir ND, McPherson JR, Cutcutache I, Poore G, Tay ST, Ooi WS, Tan VK, Hartman M, Ong KW, Tan BK, Rozen SG, Tan PH, Tan P, Teh BT (2014) Exome sequencing identifies highly recurrent MED12 somatic mutations in breast fibroadenoma. Nat Genet 46(8): $877-880$.

Lindquist KD, van Heerden JA, Weiland LH, Martin Jr JK (1982) Recurrent and metastatic cystosarcoma phyllodes. Am J Surg 144(3): 341-343.

Makinen N, Mehine M, Tolvanen J, Kaasinen E, Li Y, Lehtonen HJ, Gentile M, Yan J, Enge M, Taipale M, Aavikko M, Katainen R, Virolainen E, Bohling T, Koski TA, Launonen V, Sjoberg J, Taipale J, Vahteristo P, Aaltonen LA (2011) MED12, the mediator complex subunit 12 gene, is mutated at high frequency in uterine leiomyomas. Science 334(6053): 252-255.

Matsubara A, Sekine S, Yoshida M, Yoshida A, Taniguchi H, Kushima R, Tsuda H, Kanai Y (2013) Prevalence of MED12 mutations in uterine and extrauterine smooth muscle tumours. Histopathology 62(4): 657-661.

McGuire MM, Yatsenko A, Hoffner L, Jones M, Surti U, Rajkovic A (2012) Whole exome sequencing in a random sample of North American women with leiomyomas identifies MED12 mutations in majority of uterine leiomyomas. PLoS One 7(3): e33251.

Nielsen M, Thomsen JL, Primdahl S, Dyreborg U, Andersen JA (1987) Breast cancer and atypia among young and middle-aged women: a study of 110 medicolegal autopsies. Br J Cancer 56(6): 814-819.

Noguchi S, Yokouchi H, Aihara T, Motomura K, Inaji H, Imaoka S, Koyama H (1995) Progression of fibroadenoma to phyllodes tumor demonstrated by clonal analysis. Cancer 76(10): 1779-1785.

Reinfuss M, Mitus J, Duda K, Stelmach A, Rys J, Smolak K (1996) The treatment and prognosis of patients with phyllodes tumor of the breast: an analysis of 170 cases. Cancer 77(5): 910-916.

Sawhney N, Garrahan N, Douglas-Jones AG, Williams ED (1992) Epithelialstromal interactions in tumors. A morphologic study of fibroepithelial tumors of the breast. Cancer 70(8): 2115-2120.

Sawyer EJ, Hanby AM, Ellis P, Lakhani SR, Ellis IO, Boyle S, Tomlinson IP (2000) Molecular analysis of phyllodes tumors reveals distinct changes in the epithelial and stromal components. Am J Pathol 156(3): 1093-1098.
Sawyer EJ, Hanby AM, Rowan AJ, Gillett CE, Thomas RE, Poulsom R, Lakhani SR, Ellis IO, Ellis P, Tomlinson IP (2002) The Wnt pathway, epithelial-stromal interactions, and malignant progression in phyllodes tumours. J Pathol 196(4): 437-444.

Tan HL, Sood A, Rahimi HA, Wang W, Gupta N, Hicks J, Mosier S, Gocke CD, Epstein JI, Netto GJ, Liu W, Isaacs WB, De Marzo AM, Lotan TL (2014) $\mathrm{Rb}$ loss is characteristic of prostatic small cell neuroendocrine carcinoma. Clin Cancer Res 20(4): 890-903.

Tan PH, Jayabaskar T, Yip G, Tan Y, Hilmy M, Selvarajan S, Bay BH (2005) p53 and c-kit (CD117) protein expression as prognostic indicators in breast phyllodes tumors: a tissue microarray study. Mod Pathol 18(12): 1527-1534.

Tan PH, Tse G, Lee A, Simpson JF, Hanby AM (2012) Fibroepithelial tumours. In: Lakhani SR, Ellis IO, Schnitt SJ, Tan PH, van de Vijver MJ (eds) WHO Classification of Tumours of the Breast. pp 142-147. IARC Press: Lyon.

Tavassoli FA, Eusebi V (2009) Biphasic tumors. In: Tavassoli FA, Eusebi V (eds) vol. 10AFIP Atlas of Tumor Pathology. pp 315-340. American Registry of Pathology: Washington, DC.

Tse GM, Putti TC, Kung FY, Scolyer RA, Law BK, Lau TS, Lee CS (2002) Increased p53 protein expression in malignant mammary phyllodes tumors. Mod Pathol 15(7): 734-740.

Turunen M, Spaeth JM, Keskitalo S, Park MJ, Kivioja T, Clark AD, Makinen N, Gao F, Palin K, Nurkkala H, Vaharautio A, Aavikko M, Kampjarvi K, Vahteristo P, Kim CA, Aaltonen LA, Varjosalo M, Taipale J, Boyer TG (2014) Uterine leiomyoma-linked MED12 mutations disrupt mediatorassociated CDK activity. Cell Rep 7(3): 654-660.

Yachida S, Vakiani E, White CM, Zhong Y, Saunders T, Morgan R, de Wilde RF, Maitra A, Hicks J, Demarzo AM, Shi C, Sharma R, Laheru D, Edil BH, Wolfgang CL, Schulick RD, Hruban RH, Tang LH, Klimstra DS, Iacobuzio-Donahue CA (2012) Small cell and large cell neuroendocrine carcinomas of the pancreas are genetically similar and distinct from welldifferentiated pancreatic neuroendocrine tumors. Am J Surg Pathol 36(2): 173-184.

Yang X, Kandil D, Cosar EF, Khan A (2014) Fibroepithelial tumors of the breast: pathologic and immunohistochemical features and molecular mechanisms. Arch Pathol Lab Med 138(1): 25-36.

This work is published under the standard license to publish agreement. After 12 months the work will become freely available and the license terms will switch to a Creative Commons AttributionNonCommercial-Share Alike 4.0 Unported License.

Supplementary Information accompanies this paper on British Journal of Cancer website (http://www.nature.com/bjc) 